\title{
Novo meio seletivo-indicador para deteç̧ão de Aeromonas e Plesiomonas: ágar UNISC
}

\author{
New selective indicator medium for detection \\ of Aeromonas and Plesiomonas: UNISC agar
}

\author{
Marion Pereira da Rocha ${ }^{1}$, Liliane A. Scheid ${ }^{2}$ e Sydney Hartz Alves ${ }^{2}$
}

\begin{abstract}
RESUMO
Avaliou-se um novo meio seletivo-indicador (ágar UNISC) para o isolamento de enteropatógenos clássicos e Aeromonas e Plesiomonas shigelloides. A capacidade de fermentação da xilose é indicada pela coloração amarela (fermentadores) ou azul (não fermentadores) que, aliada à prova da oxidase, constitui-se em indicador para a detecção de Aeromonas spp e Plesiomonas shigelloides. A produtividade e seletividade, avaliadas pelos índice de contagem absoluta e índice de contagem relativa indicam-no como uma alternativa aos coprocultivos clássicos porque permite, num só meio, o isolamento de Escherichia coli, Shigella spp, Salmonella spp, bem como, Aeromonas spp e Plesiomonas shigelloides, favorecendo o diagnóstico laboratorial das gastroenterites.
\end{abstract}

Palavras-chaves: Aeromonas. Plesiomonas. Coprocultivo. Meio de cultura.

\section{ABSTRACT}

We evaluated a new selective indicator medium (UNISC Agar) for isolation of classical enteropathogens, Aeromonas spp and Plesiomonas shigelloides. The xylose fermentation capacity is indicated by a yellow color (fermenting agents) or blue (no fermenting agent). This, together with the oxidase test, establishes it as an indicator for detecting Aeromonas and Plesiomonas shigelloides. Its productivity and selectivity, as assessed using the absolute count index and relative count index, indicate it as an alternative to the classical feces culturing media. This is because, in a single medium, it enables isolation of Escherichia coli, Shigella spp and Salmonella spp, in addition to Aeromonas and Plesiomonas shigelloides, thereby favoring the laboratory diagnosis of gastroenteritis.

Key-words: Aeromonas. Plesiomonas. Feces culture. Culture medium.

O diagnóstico laboratorial das gastroenterites causadas por Aeromonas spp e Plesiomonas shigelloides é dependente do emprego de meios de cultura específicos para seu isolamento. o ágar MacConkey e o ágar Salmonella-Shigella (SS) ou similares, são rotineiramente utilizados nos coprocultivos e, nestas condições, a detecção de Aeromonas spp e Plesiomona shigelloides fica comprometida ${ }^{810}$.

0 presente estudo foi objetivado a avaliar um novo meio seletivo-indicador capaz de detectar os enteropatógenos clássicos e, ainda, Aeromonas e Plesiomonas shigelloides. 0 meio proposto (ágar UNISC) homenageia a Universidade de Santa Cruz do Sul (Santa Cruz do Sul, RS) onde o mesmo foi idealizado.

Um total de 30 isolados de Aeromonas hydrophila e 30 de Plesiomonas shigelloides foram estudados. 0 estudo também incluiu Escherichia coli $\left(\mathrm{n}^{\mathrm{0}}=12\right)$, Pseudomonas aeruginosa $\left(\mathrm{n}^{0}=5\right)$, Proteus mirabilis $\left(\mathrm{n}^{\mathrm{0}}=10\right)$, Klebsiella pneumoniae $\left(\mathrm{n}^{\mathrm{0}}=15\right)$, Enterobacter spp $\left(\mathrm{n}^{\mathrm{0}}=10\right)$, Salmonella $\mathrm{spp}$ $\left(\mathrm{n}^{-0}=12\right)$, Shigella flexneri $\left(\mathrm{n}^{\mathrm{0}}=8\right)$, Shigella sonne $i$ $\left(\mathrm{n}^{\mathrm{0}}=5\right)$, Edwardsiella tarda $\left(\mathrm{n}^{\mathrm{0}}=1\right)$ e Enterococcus faecalis $\left(\mathrm{n}^{\underline{0}}=5\right)$ Pseudomonas aeruginosa $\left(\mathrm{n}^{\mathrm{0}}=5\right)$. A identificação destes isolados foi previamente realizada de acordo com Altweeg, 19993. Como controle de qualidade incluiu-se: Aeromonas bydrophila ATCC 7966, Aeromonas caviae ATCC 15468, Plesiomonas shigelloides ATCC 14029, Staphylococcus aureus ATCC 25923, Escherichia coli ATCC 25922 e Pseudomonas aeruginosa ATCC 27853. Os isolados foram obtidos no Departamento de Microbiologia e Parasitologia da Universidade Federal de Santa Maria.

1. Universidade de Santa Cruz. Santa Cruz do Sul, RS, Brasil. 2. Departamento de Microbiologia e Parasitologia, Universidade Federal de Santa Maria, Santa Maria, RS. Endereço para correspondência: Prof. Sydney Hartz Alves. Rua Andradas 1985/201, 97010-033 Santa Maria, RS.

Telefax: $55553220-8906$

e-mail: hartzsa@smail.ufsm.br

Recebido para publicação em 14/01/2008

Aceito em 29/07/2008 
A composição do meio proposto (ágar UNISC) incluiu: a) Base: peptona bacteriológica* $5 \mathrm{~g}$, extrato de carne* $3 \mathrm{~g}$, azul de bromotimol* 0,03g, cristal violeta* $0,001 \mathrm{~g}$, L-cistina* $0,13 \mathrm{~g}$, ágar bacteriológico* $13 \mathrm{~g}$ e $900 \mathrm{ml}$ de água destilada. Volumes de $180 \mathrm{ml}$ do meio base fundido eram distribuídos em erlenmeyers e, a seguir, autoclavados. A base era conservada a $4^{\circ} \mathrm{C}$.; b) inclusão da $\mathrm{D}(+)$ xilose* $10 \%$ : $10 \mathrm{~g}$ de xilose era solubilizada em volumes de 100ml de água destilada, esterilizada por filtração (membrana millipore $0,22 \mu \mathrm{m}$ ) e aliquotada em volumes de $20 \mathrm{ml}$, sendo conservada em freezer. 0 meio final era obtido pela inclusão de $20 \mathrm{ml}$ da solução de xilose $10 \%$ a $180 \mathrm{ml}$ da base estéril e fundida; após rápida homogeneização, o meio era distribuído em placas de Petri. 0 pH final do meio é de 7,2 $\pm 0,2$. Para a avaliação do comportamento das bactérias intestinais no ágar UNISC, os microrganismos eram, inicialmente, semeados no ágar MacConkey e, após $24 \mathrm{~h}$ de incubação a $35^{\circ} \mathrm{C}$, suspensões eram preparadas para a obtenção de inóculos contendo $1 \times 10^{4}$ células/mL em solução fisiológica. Staphylococcus aureus e Enterococcus faecalis eram semeados em ágar sangue e, deste, obtinha-se as suspensões como para os demais microrganismos. A seguir, volumes de $10 \mu \mathrm{L}$ de cada suspensão bacteriana eram semeados por esgotamento no ágar UNISC, e as placas incubadas a $35^{\circ} \mathrm{C}$ durante $24 \mathrm{~h}$. Para avaliação da produtividade e seletividade empregou-se os índice de crescimento absoluto (ICA) e índice de crescimento relativo (ICR): a partir da avaliação do crescimento bacteriano, no Método Ecométrico ${ }^{11}$, determinou-se o ICA para o ágar UNISC e para o ágar BHI. Cultivos de Aeromonas bydrophila ATCC 7966, Plesiomonas shigelloides ATCC 14029, Aeromonas caviae ATCC 15468, Escherichia coli ATCC 25922, Salmonella setubal ATCC 19196 e Shigella flexneri (isolado clínico) foram empregados. 0 índice de crescimento relativo representa 0 quociente entre o ICA no meio de referência (ágar BHI) pelo ICA no meio proposto (ágar UNISC). 0 isolamento de Aeromonas spp e Plesiomonas shigelloides era realizado a partir de material fecal onde suspensões de enteropatógenos contendo 1 x $10^{4}$ células $/ \mathrm{mL}$ eram artificialmente contaminadas com pequena porção de fezes humanas normais (submetidas a coprocultivo convencional) e semeadas (10 $\mu \mathrm{L})$ no ágar UNISC. Após $24 \mathrm{~h}$ de incubação a $35^{\circ} \mathrm{C}$ os diferentes tipos coloniais eram avaliados. A Reação da oxidase foi empregada para detecção do sistema citocromo oxidase $e^{9}$.

As características fenotípicas das colônias bacterianas após 24 horas de incubação no ágar UNISC foram: amarelas para os microrganismos fermentadores da xilose e azuis para os não fermentadores deste carboidrato. Os crescimentos deAeromonas bydrophila, Plesiomonas shigelloides, Shigella flexneri, Shigella sonnei, Edwardsiella tarda, Proteus mirabilis e Pseudomonas aeruginosa apresentaram-se como colônias azuis devido a não fermentação da xilose. Por outro lado, Escherichia coli, Salmonella spp, Klebsiella pneumoniae e Enterobacter spp evidenciaram colônias amarelas devido a fermentação da xilose.

A produtividade e seletividade do ágar UNISC foi estimada com base na determinação do ICA e do ICR: Aeromonas hydrophila

*Peptona bacteriológica (HIMEDIA); *extrato de carne (OXOID); *azul de bromotimol (VETEC); *ágar bacteriológico (HIMEDIA); *xilose (VETEC); *L-cistina(VETEC).
ATCC 7966 (ICA no BHI= 4,0; ICA no ágar UNISC =3,8; ICR= 0,95); Aeromonas caviae ATCC 15468 (ICA no $\mathrm{BHI}=4,0$; ICA no ágar UNISC = 3,8; ICR= 0,95); Plesiomonas shigelloides ATCC 14029 (ICA no BHI= 4,0; ICA no ágar UNISC= 3,6; ICR= 0,90); Salmonella setubal ATCC (ICA no BHI= 5,0; ICA no ágar UNISC = 4,0; ICR $=0,80$ ); Escherichia coli ATCC 25922 (ICA no BHI = 5,0; ICA no ágar UNISC $=3,8$; ICR= 0,76); Shigella flexneri (ICA no BHI= 4,0; ICA no ágar UNISC= 3,8; ICR= 0,95). Staphylococcus aureus e Enterococcus faecalis não se desenvolveram na superfície do ágar UNISC devido a ação inibitória do cristal violeta sobre microrganismos Gram positivos. Os cultivos das suspensões contaminadas com material fecal contendo duas espécies resultaram bem diferenciados quando a combinação envolvia fermentador/não fermentador. Quando a combinação, era com dois não fermentadores (ex: Proteus mirabilis e Aeromonas hydrophila) a prova da oxidase só era positiva para Aeromonas spp, o mesmo ocorrendo quando se empregava Plesiomonas shigelloides. No ágar UNISC Pseudomonas aeruginosa (colônias azuis) foi, como no Mac Conkey, de fácil suspeição. 0 ágar UNISC fundamenta-se na incapacidade dos gêneros Aeromonas e Plesiomonas em fermentar a xilose; isto se constitui numa vantagem por ocasião da prova da oxidase, pois, não havendo queda do pH (ausência de formação de ácidos pela fermentação) Aeromonas e Plesiomonas evidenciam positividade a esta prova ${ }^{1}$ sendo esta, um dos critérios fenotípicos essenciais nos fluxogramas de identificação de bacilos Gram negativos 5 . 0 gênero Shigella também é detectado como colônias azuis, todavia, a prova da oxidase resulta negativa para este gênero. Os enteropatógenos fermentadores da xilose são Escherichia coli e Salmonella spp. Objetivando-se inibir o crescimento em véu de Proteus spp, comensais nas fezes humanas, incluiu-se, na composição do ágar UNISC, a L-cistina $(0,13 \mathrm{~g} / \mathrm{L})$ que foi efetiva neste propósito ${ }^{13}$.

No diagnóstico microbiológico das gastroenterites bacterianas, 0 ágar Mac Conkey e o ágar Salmonella-Shigella são, em conjunto, os meios mais empregados pelos laboratórios clínicos ${ }^{10}$. Aeromonas spp e Plesiomonas shigelloides não têm desenvolvimento adequado no Mac Conkey, podendo apresentar-se como colônia lactose positiva ou negativa. A fermentação da lactose e a presença de sais biliares do meio, por outro lado, constituem-se em interferentes à prova da oxidase, recurso útil na detecção de Aeromonas spp e Plesiomonas shigelloides ${ }^{6}{ }^{10}$. Este contexto impõe a necessidade de inclusão de um terceiro meio de cultura, específico a estes patógenos ágar sangue-ampicilina ${ }^{7}$, Pril-xilose-ampicilina ágar (PXA $)^{12}$, cefsulodin-irgasan-novobiocina ágar ${ }^{2}$, são possibilidades alternativas bem estudadas. A inclusão da ampicilina é um recurso que tem sido utilizado para selecionar Aeromonas spp e Plesiomonas shigelloides resistentes a este agente, entretanto, estirpes sensíveis a esta penicilina já foram relatadas ${ }^{4}{ }^{14}$.

Neste contexto, os coprocultivos apresentam-se limitados na detecção de Aeromonas spp e Plesiomonas shigeloides seja pela necessidade de inclusão de um novo meio seletivo e específico, onerando os coprocultivos, seja pela incapacidade dos mesmos em detectar estes patógenos, devido a variações na suscetibilidade à ampicilina. 0 ágar UNISC constitui-se em proposta racional, todavia, requerendo ainda, validação em 
ensaio clínico porque poderá substituir dois meios de cultura (ágar MacConkey e ágar Salmonella-Shigella) acrescida da vantagem de diagnosticar também gastroenterites causadas por Aeromonas spp e Plesiomonas shigelloides.

\section{REFERÊNCIAS}

1. Abbott S, Cheung WKW, Janda JM. The genus Aeromonas: biochemical characteristics, atypical reactions, and phenotypic identification schemes. Journal of Clinical Microbiology 41: 2348-2357, 2003.

2. Altorfer R, Altweeg M, Zollinger-Iten J, Von Graevenitz A. Growth of Aeromonas spp. on cefsulodin-irgasan-novobiocin agar selective for Yersinia enterocolitica. Journal of Clinical Microbiology 22: 478-480, 1985.

3. Altweeg M, Geiss HK. Aeromonas as a human pathogen. Critical Reviews in Microbiology 16: 235-286, 1989.

4. Carnahan AM, Chakraborty T, Fanning GR, Verma D, Ali A, Janda JM, Joseph SW. Aeromonas trota sp. Nov., an ampicilin-susceptible species isolated from clinical specimens. Journal of Clinical Microbiology 29: 1206-1210, 1991.

5. Guerra IMF, Fadanelli R, Figueiró M, Schreiner F, Delamare APL, Wolheim C, Costa SOP, Echeverrigaray S. Aeromonas associated diarrhoeal disease in south Brazil: prevalence, virulence factors and antimicrobial resistance. Brazilian Journal Microbiology 38:638-643, 2007.
6. Hunt LK, Overman TL, Otero RB. Role of $\mathrm{pH}$ in oxidase variability of Aeromonas hydrophila. Journal of Clinical Microbiology 13: 1054-1059, 1981.

7. Kay BA, Guerrero CE, Bradley Sack R. Media for the isolation of Aeromonas hydrophila. Journal of Clinical Microbiology 22: 888-890, 1985.

8. Khardori N, Fainstein V. Aeromonas and Plesiomonas as etiological agents. Annual Review Microbiology 42: 395-419, 1988.

9. Landerdale T, Chapin KC, Murray PR. Reagents. In: Murray PR, Baron EJ, Pfaller MA, Tenover FC, Yolken RH (eds) Manual of Clinical Microbiology, $7^{\text {th }}$ edition, ASM Press, Washington, p.1665, 1999.

10. Mishra S, Nair GB, Bhadra RK, Sikder SN, Pal SC. Comparison of a selective media for primary isolation of Aeromonas species from human and animal feces. Journal of Clinical Microbiology 25: 2040-2043, 1987.

11. Mossel DAA. Microbiologia de los Alimentos. Zaragoza, Editorial Acribia, 1982 .

12. Rogol M, Sechter I, Grimberg H, Gerichter CB. Pril-xylose-ampicilin agar, a new selective medium for the isolation of Aeromonas bydrophila. Journal of Medical Microbiology 12: 229-232, 1979.

13. Sandys GH. A new method for prevening swarming of Proteus sp with a description of a new medium suitable for use in routine laboratory practice. Journal of Medical and Laboratory Technology 17: 224-233, 1960.

14. Von Graevenitz A, Bucher C. Evaluation of differential and selective media for isolation of Aeromonas and Plesiomonas spp. from human feces. Journal of Clinical Microbiology 17: 16-21, 1983. 